\title{
Development and Test of an Experimental Apparatus to Study Thermal-Choking in Ideal Gases and Self-decomposition in Superheated $\mathrm{N}_{2} \mathrm{O}$
}

\author{
Patrick Lemieux ${ }^{1}$, Alberto Fara ${ }^{2}$, Pablo Sanchez ${ }^{2}$ and William Murray ${ }^{3}$ \\ 1. California Polytechnic State University, San Luis Obispo, CA, 93407, USA \\ 2. Politecnico di Torino, Turin 10129, Italy \\ 3. California Polytechnic State University, San Luis Obispo, CA, 93407, USA
}

Received: August 30, 2014 / Accepted: October 10, 2014 / Published: January 31, 2015.

\begin{abstract}
N}_{2} \mathrm{O}$ represents a popular oxidizer for hybrid rocket motors for a variety of reasons, including safety, ease of access and self-pressurization. It is often used as a saturated two-phase fluid in these applications to take advantage of self-pressurization. Recent interest in using this oxidizer in regeneratively cooled engines requires a detailed heat transfer process analysis to the coolant, in order to quantify performance. Since the injection of $\mathrm{N}_{2} \mathrm{O}$ typically takes place in the two-phase region, our study focuses on heat transfer rates in this region, and extends the region to include superheated vapor. This analysis is critical for these cooling applications, because the exothermic decomposition nature of $\mathrm{N}_{2} \mathrm{O}$ also means that unchecked heating in the superheated region may result in a runaway reaction in the cooling passages. Furthermore, provided that sufficient heat transfer rates are available, $\mathrm{N}_{2} \mathrm{O}$ is expected to accelerate in the cooling passages due to Rayleigh flow effects much like those of a calorically perfect gas. The proximity of superheated $\mathrm{N}_{2} \mathrm{O}$ to its saturated vapor curve, at the conditions studied here, makes the suitability of a perfect gas model questionable, but that benchmarks is still useful. This paper presents the development of an experimental apparatus (a "Rayleigh tube"), specifically designed to study this problem, and test the analytical methods developed to model it. Since we focus on the development of the apparatus, the data presented were uses primarily calorically perfect gas surrogates, but the goal is to apply the apparatus and method to $\mathrm{N}_{2} \mathrm{O}$. The design and construction of the Rayleigh tube is presented, along with preliminary results with perfect gases. Finally, we present preliminary results on heated $\mathrm{N}_{2} \mathrm{O}$ flow. Using a simple model for predicted dry-out point, we investigate where superheating may be expected to occur. We present estimates of critical heating and compare them to the heat required to achieve self-decomposition.
\end{abstract}

Key words: Self-decomposition, $\mathrm{N}_{2} \mathrm{O}$, Rayleigh apparatus.

\section{Nomenclature}

$\begin{array}{ll}\text { CHF } & \text { Critical heat flux } \\ \mathrm{N}_{2} \mathrm{O} & \text { Nitrous oxide } \\ \text { IAF } & \text { Inverted annular flow } \\ \text { SCR } & \text { Silicon-controller rectifier }\end{array}$

\section{Introduction}

The combination of experimental, analytical and numerical modeling is the best way to obtain heat transfer coefficient data for two-phase flow of fluids,

\footnotetext{
Corresponding author: Patrick Lemieux, professor, research field: mechanical engineering. E-mail: plemieux@calpoly.edu.
}

such as $\mathrm{N}_{2} \mathrm{O}$, and thereby prevent dangerous self-decomposition excursions [1]. These results and modeling techniques will allow us to develop an appropriate tool for the modeling of $\mathrm{N}_{2} \mathrm{O}$ cooling in aerospike nozzles.

Accordingly, our two main technical objectives in this project were:

(1) Develop and characterize an experimental apparatus for tests on $\mathrm{N}_{2} \mathrm{O}$ that minimizes the uncertainties. The specifications for this apparatus are that it should be simple, flexible and sufficiently rugged to withstand changes in setup and operating conditions, and should be modular and relatively easy to replace or 
rebuild, making it a more appropriate platform for a (possibly) destructive decomposition study.

(2) Develop models for the thermo fluid behavior of $\mathrm{N}_{2} \mathrm{O}$ that characterize its performance in cooling applications.

The primary experimental apparatus for this project consists of an electrically-heated, instrumented, straight-pipe flow device suitable for Rayleigh, or heat driven, flow experiments. Electrical heating was chosen so that the power input could be easily measured and controlled. A concept drawing of the apparatus is shown in Fig. 1. Each set of instrumentation ports includes a thermocouple for measuring coolant temperature, a pressure tap for measuring static pressure, and a thermocouple for measuring temperature of the copper wall of the pipe. The plan was to develop, test and characterize this apparatus with air (for its low cost) and helium (as a surrogate for a perfect gas) before using it to characterize the behavior of $\mathrm{N}_{2} \mathrm{O}$. This paper discusses primarily the use of the apparatus with air and helium; a follow-up paper will discuss its use with $\mathrm{N}_{2} \mathrm{O}$ in more detail.

\section{Design of Apparatus}

The basic dimensions of the apparatus (that is, diameter and length) are a fundamental function of the maximum flow rate that we felt comfortable with testing (primarily with $\mathrm{N}_{2} \mathrm{O}$ ), and with length to the critical point, over the full gamut of tests that we expected to run. Cost of manufacturability and materials necessarily scaled with length also, so in the final analysis, we chose to build an apparatus with an internal diameter of 0.245 inches, and a total length of 87.50 inches (i.e., maximum $L / D$ for the apparatus of about 350, high enough for most Rayleigh analysis, without prohibitively high heating load demands, which we arbitrarily capped at $3 \mathrm{~kW}$, again in deference to the system cost and a desire to operate on the $220 \mathrm{~V}$ electrical service available to us). We chose copper for the tube material, for ease of heat transfer to

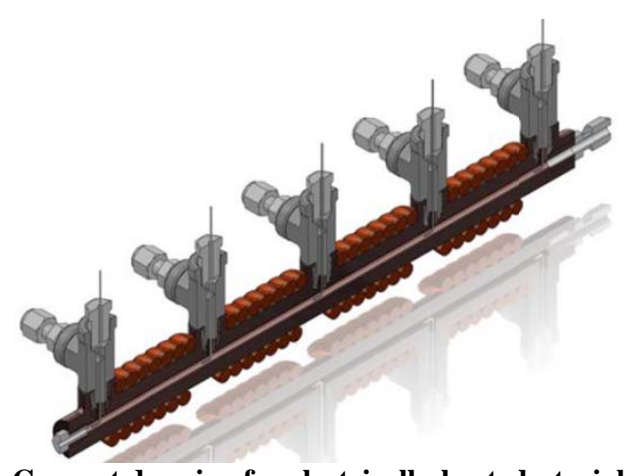

Fig. 1 Concept drawing for electrically-heated, straight-pipe Rayleigh apparatus.

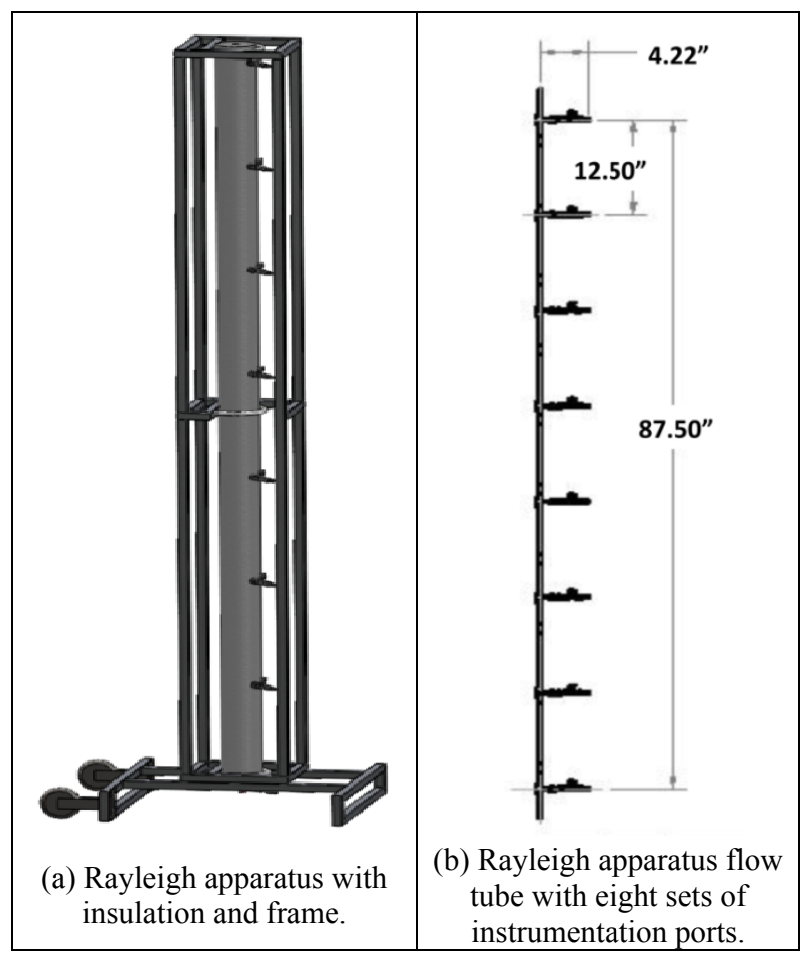

Fig. 2 Rayleigh apparatus.

the heated gas. The apparatus was to be subdivided into even segments, as shown in Fig. 1, to quantify state changes in either Fanno (friction-driven) or Rayleigh (heat-driven) mode. Figs. 2-5 illustrate the layout of instruments on our Rayleigh tube and fittings used to maintain leak-free operation at high operating pressures. Three measurements are made at each instrumentation port: fluid temperature, fluid pressure, and copper wall temperature. The thermocouple for measuring copper wall temperature is at the same axial location, but is embedded in the pipe wall on the opposite side of the pipe. 


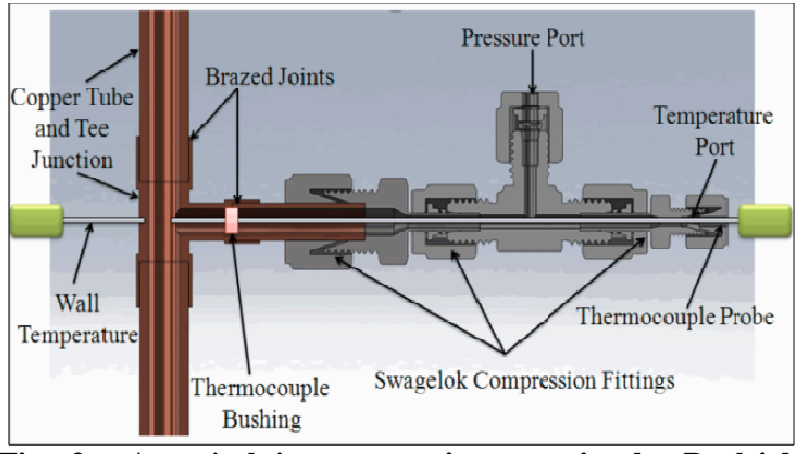

Fig. 3 A typical instrumentation port in the Rayleigh apparatus.

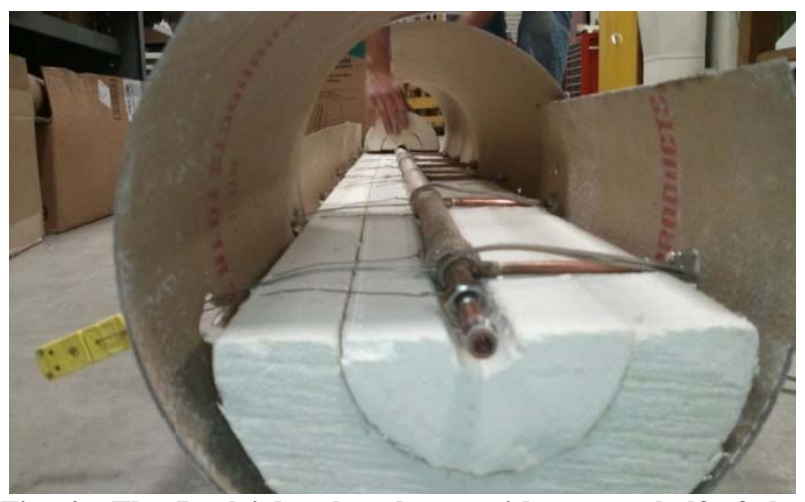

Fig. 4 The Rayleigh tube, shown with on one-half of the calcium silicate insulation.

To the extent possible, the Rayleigh apparatus was designed to contain mostly off-the-shelf components. Electrical heat tape with flexible fiberglass insulation was chosen as the heat source, and the most powerful heat tape found is capable of producing $78 \mathrm{~W} / \mathrm{ft}$ of heat tape. However, through a separate series of tests, and with appropriate cooling (as expected when flowing a gas in the tube), we established that we could obtain at least $424 \mathrm{~W} / \mathrm{ft}$ of heat input along the pipe by using a double-layer butted wrap for the heat tape, corresponding to a total heat flow rate of just above 3 $\mathrm{kW}$. Subsequent experiments on the completed Rayleigh apparatus have shown that we can in fact generate a heat load of almost $4 \mathrm{~kW}$.

\section{Mass Flow Rate Estimates for $\mathrm{N}_{2} \mathrm{O}$}

For a representative $\mathrm{N}_{2} \mathrm{O}$ process path during our experiments, we expect the change in enthalpy from entrance into to the vapor dome to the superheated state to be approximately $185 \mathrm{~kJ} / \mathrm{kg}$. This corresponds to

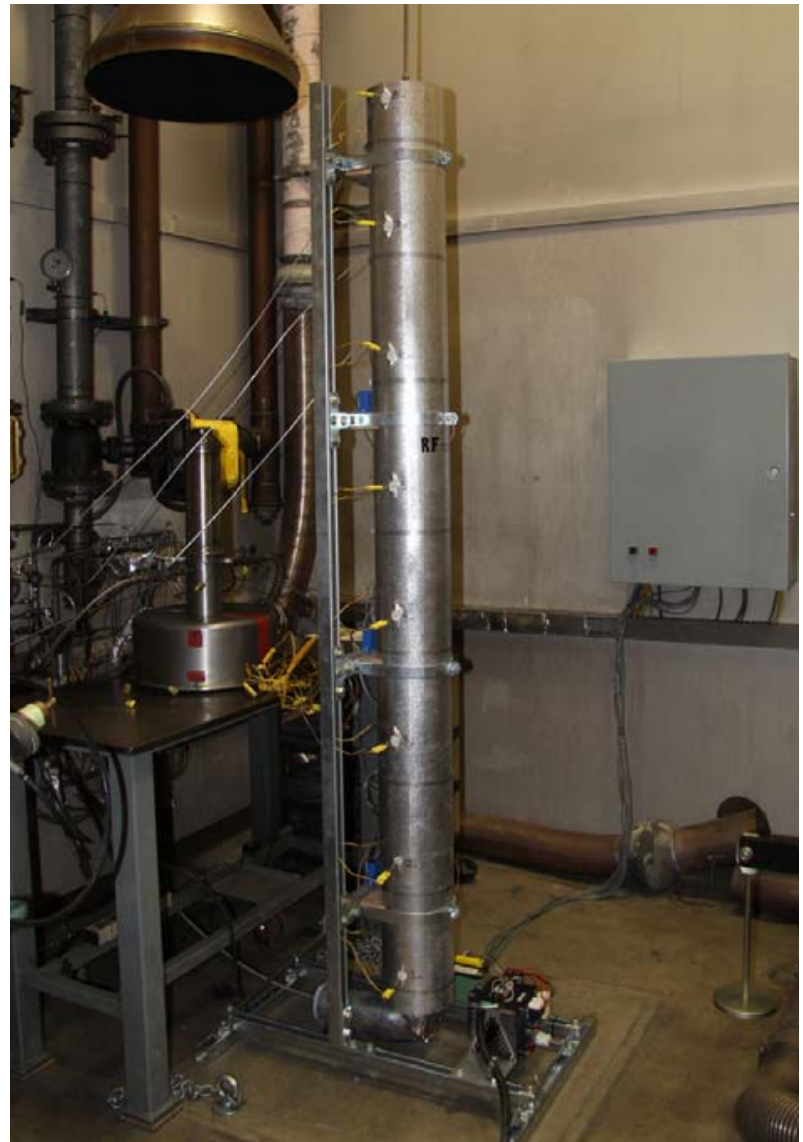

Fig. 5 The Rayleigh flow apparatus installed in the test cell at Cal Poly.

pressure throttling from about $5 \mathrm{MPa}$ upstream of the apparatus, to $3 \mathrm{MPa}$ at the tube inlet, and a continuous pressure drop through the apparatus varying with heat input. Given a maximum of approximately $3 \mathrm{~kW}$ of heat input from the heat tape used on our apparatus, the maximum flow rate that takes $\mathrm{N}_{2} \mathrm{O}$ to a superheated state at the exit of the pipe is:

$$
\dot{m}=\frac{\dot{q}}{\Delta h}=0.016 \mathrm{~kg} / \mathrm{s}=0.036 \mathrm{lb} / \mathrm{s}
$$

To allow headroom to reach decomposition of the $\mathrm{N}_{2} \mathrm{O}$, our target $\dot{m}$ for $\mathrm{N}_{2} \mathrm{O}$ is $0.02 \mathrm{lb}_{\mathrm{m}} / \mathrm{s}$. This target flow rate corresponds to a relatively low flow velocity for a pipe having an internal diameter of nominally 0.25 inches. This low flow velocity lowers the Fanno component of the pressure drop, thereby making the Rayleigh component of the pressure drop larger in a relative sense, and therefore easier to distinguish. This low $\mathrm{N}_{2} \mathrm{O}$ flow rate is also good from a safety point of 
view because it limits the amount of $\mathrm{N}_{2} \mathrm{O}$ expelled from the Rayleigh apparatus during an experiment.

\section{Apparatus Verification Procedure}

\subsection{Pressure Test}

The final Rayleigh apparatus was hydrostatically tested to $1,300 \mathrm{psi}$, and showed no sign of water leakage. The maximum operating pressure (with $\mathrm{N}_{2} \mathrm{O}$ ) is not expected to exceed $750 \mathrm{psig}$, and given its two phase nature, the water leak test is probably sufficiently valid. This is not necessarily true for gas tests, which are required for characterization of our apparatus.

We tested the apparatus under air pressure of up to 800 psig (in a secure Test Cell laboratory environment), and observed slow leaks in the apparatus, which we set to quantify. We also developed a method for quantifying the volume of the apparatus as-built. This volume is not easy to determine accurately, given manufacturing tolerances and the manifold of small tee-tubes used for differential pressure measurements (visible in Figs. 1-4).

\subsection{As-Built Volume}

The actual, as-built apparatus volume is an important parameter. For instance, it cross references the total fluid mass in the tube (measured indirectly, by integrating the rate output of a Coriolis Mass Flow meter) with an equation of state for average density. To be valuable, this estimate must be accurate, and may significantly differ from the nominal design value, $11.687 \times 10^{-5} \mathrm{~m}^{3}$ for the straight-pipe volume in this case. Yet, measuring this volume directly is daunting, given the length scale of the apparatus and many tube manifolds connected to it for sensing purposes. An experimental volume calculation technique was developed to take advantage of "ideal gas" fluid property variations during tube pressurization. The procedure consists of isolating the tube, and filling it with air from a large reservoir up to a predetermined pressure, all the while recording its temperature and pressure. The method is summarized below:
Compute density prior to filling:

$$
\frac{m_{1}}{V}=\frac{p_{1}}{\mathrm{R} T_{1}}
$$

Pressurize the tube to a new state point:

$$
\frac{m_{2}}{V}=\frac{p_{2}}{\mathrm{R} T_{2}}
$$

The added mass in the tube may be found by integrating the flow rate through the Coriolis meter, and relates the mass at the two states:

$$
\Delta m=m_{2}-m_{1}
$$

where, $p, T, m$ are the pressure, temperature and mass inside the pipe, respectively, $\mathrm{R}$ is the specific gas constant (air in this case), and $V$ is the desired volume. Note that $p$ and $T$ are obtained through the average measurements of the eight ports, and $\rho$ is then calculated through the equation of state. The only unknowns remaining are $m_{1}, m_{2}$ and $V$, so that the set of three equations has a solution, and we can compute the apparatus volume.

To reduce the possibility of bias from the instruments, the procedure was repeated many times, at different pressures, until a normal distribution curve of volume was obtained. Two of these curves are shown in Figs. 6 and 7, for tube pressurization to 100 psig and 300 psig, respectively.

The mean volume obtained from this method gave a most-likely, as-built volume of $14.5 \times 10^{-5} \mathrm{~m}^{3}$. Subtracting the known volume for the straight pipes between the shutoff valve at the bottom and the

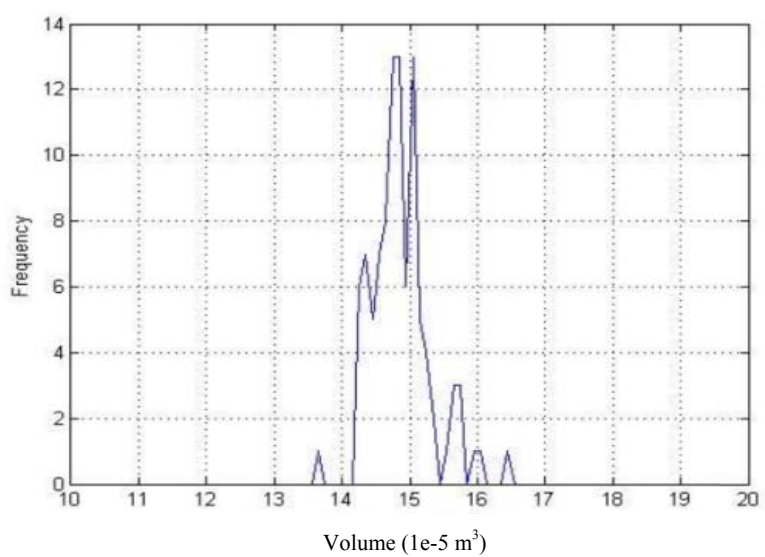

Fig. 6 Experimental volume values distribution for 100 experiments to 100 psi. 


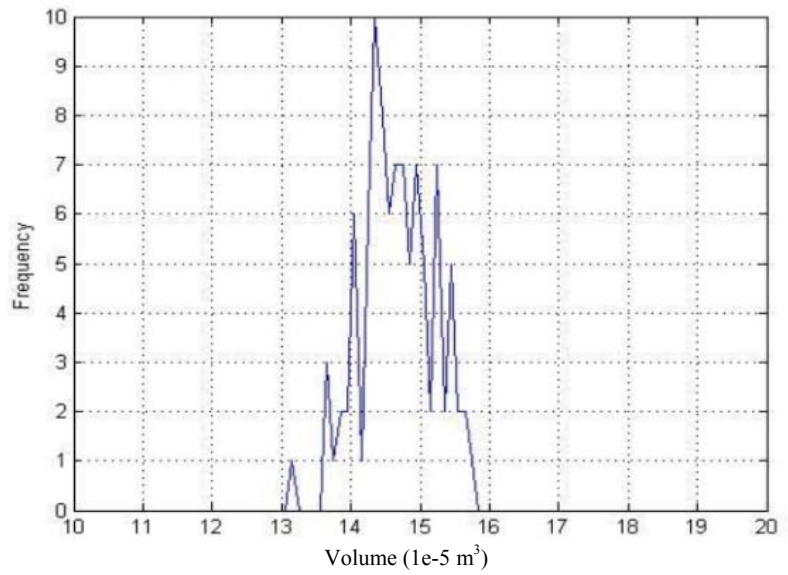

Fig. 7 Experimental volume values distribution for 100 experiments to 300 psi.

apparatus, and the same at the top, we obtain our best-estimate of the apparatus volume: $V_{\text {experimental }}=$ $12.0 \times 10^{-5} \mathrm{~m}^{3}$, or approximately $2.7 \%$ larger than that of the nominal, calculated volume of the apparatus.

\subsection{Effective Leak Area Calculation}

Once pressurized to 800 psig with air and isolated, the apparatus was found to leak at a (initial) rate of about $2.5 \mathrm{psi} / \mathrm{sec}$. We set to correlate this pressure drop with an estimated effective leak area size, which represents the sum area of all the sites where gas may escape.

Given the high pressure drop, we consider choked flow across each actual leak orifice. The effective leaks area $\left(A_{e f f}\right)$ is then modeled as:

$$
\begin{gathered}
\dot{m}(t) \leftarrow\left\{\begin{array}{c}
T_{t}=\frac{\gamma+1}{2} T^{*} \\
u^{*}=\sqrt{\gamma \mathrm{R} T^{*}}=\sqrt{\frac{2 \gamma \mathrm{R} T_{t}}{\gamma+1}} \\
\rho^{*}=\frac{p^{*}}{\mathrm{R} T^{*}}=\frac{p_{t}}{\mathrm{R} T_{t}}\left(\frac{2}{\gamma+1}\right)^{\frac{1}{1-\gamma}} \\
\dot{m}(t)=\left(\frac{2}{\gamma+1}\right)^{\frac{1}{1-\gamma}} \sqrt{\frac{2 \gamma}{(\gamma+1) \mathrm{R} T_{t}(t)}} P_{t}(t) A_{\text {eff }}
\end{array}\right.
\end{gathered}
$$

$P_{t}$ and $T_{t}$ versus time data are obtained through a series of experiments on the tube. The value for $\gamma$, a polytropic constant in this case, is found empirically. Finally, the leak area is inferred by matching the actual mass flow rate and pressure drop data with the curve prescribed by the perfect gas model, as shown in Figs. 8 and 9 , respectively. We thus establish that in our case, the effective leak area is on the order of $1.9 \times 10^{-10} \mathrm{~m}^{2}$. More importantly, the procedure described here allows for a relatively simple technique to monitor changes in effective leak area, which may be due to loosening of fittings, thermal expansion, wear, thread damage, etc., over time, and the effect of any change that we choose to impart on the apparatus. The same method could be applied with improved accuracy, if required, by using a gas with a smaller molecular structure, for example helium. For the purposes of our characterization exercise, air was considered sufficiently accurate.

\section{Results}

With the apparatus properties suitably characterized,

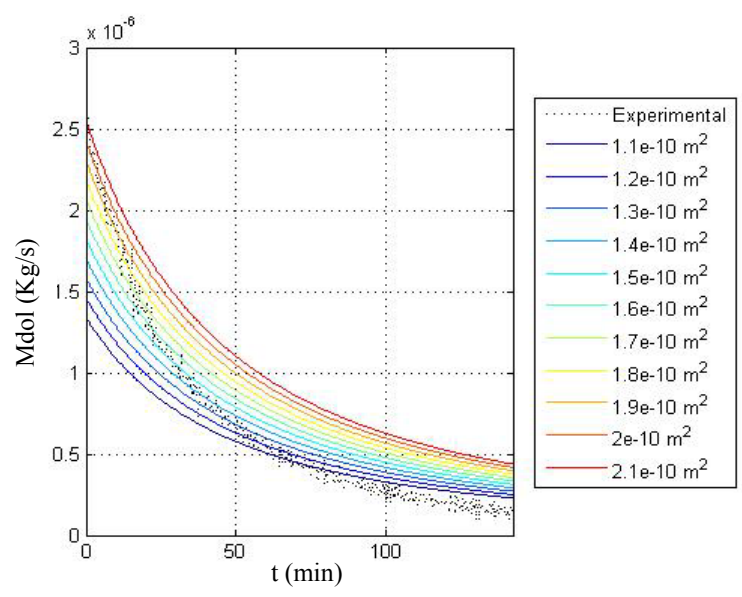

Fig. $8 \dot{m}$ curves for different $A_{\text {eff }}$.

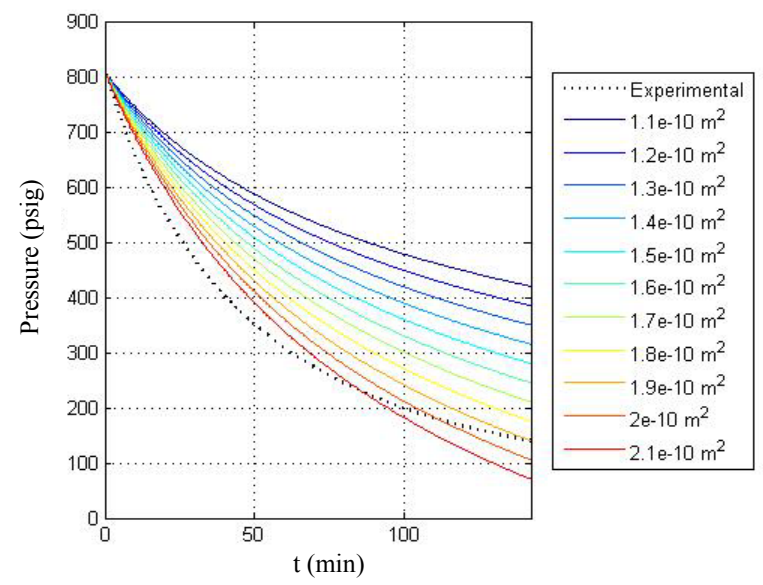

Fig. 9 Pressure drop curves, for different $\boldsymbol{A}_{\text {eff }}$. 
we ran two experiments with air, at different pressures and mass flow rate, with heat input of approximately $3.5 \mathrm{~kW}$. The result of these runs is presented below.

\section{Predictive Model for Perfect Gas Behavior}

The theory behind the behavior of friction-driven ("Fanno") and heat-driven ("Rayleigh") perfect gas flows is well-established [2]. Using an appropriate perfect gas surrogate, therefore, enables us to directly test our ability to capture the unique features of these flows, by verifying our results against accepted theoretical models, something that cannot be readily carried out with more exotic fluids, such as two-phase $\mathrm{N}_{2} \mathrm{O}$. A great perfect gas surrogate for this purpose is helium: its specific heats remain constant over a large range of temperature, and its properties are accurately modeled by the Ideal Gas Law over a large range of conditions.

Having established a basic experimental framework (basic design dimensions for the apparatus, instrument layout, flow rate capabilities, as-built volume, etc.), a perfect gas surrogate was used to characterize the apparatus friction factor. This is a function of surface roughness and Reynolds number, using a perfect gas surrogate to determine its value sets it for two-phase flows studies as well.

\subsection{Fanno Flow Analysis}

In purely friction-driven, or Fanno flow, the static pressure and temperature along the flow pipe are not independent, but instead are a function of the pipe "effective" surface roughness and the stagnation temperature at inlet. By measuring both the gas temperature and pressure, at the same location, this gives us an indication of the quality of the resolution of the instrument, and whether the setup is properly calibrated. We used the following method, adapted from calorically perfect ideal-gas Fanno theory, and conservation of mass and energy.

Define the mass flux $G$ (mass flow rate per unit area):

$$
G=\rho \cdot V
$$

Using the subscript " 0 " to denote the stagnation state, then, conservation of energy dictates that:

$$
T_{0}=T+\frac{G^{2} \cdot T^{2}}{2 C_{p}(P / \mathrm{R})^{2}}
$$

where, $\mathrm{R}$ represents the specific gas constant of the perfect gas, and $P$ and $T$ are the static pressure and temperature, respectively, and both are being measured in apparatus. So, for a given entry stagnation temperature in the apparatus, also measured, each measurement of temperature should be associated with a unique value of pressure, and vice-versa, regardless of the physical level of pipe friction. This provides a baseline method for verifying our data: we use the first data point (pressure and temperature, and mass flux) to determine the stagnation condition, and use the set of subsequent measured pressure points to determine how well our thermocouples are tracking the expected temperature field in the field. We repeat the exercise, using the temperature data to predict pressure. Ideally, the two sets of data match in both case, but the exercise illustrates if there are variations in the predicted data set. Figs. 10-13 show the results of this analysis. This is due to the variability in temperature measurements, where the instrument noise is of the same order as the change in temperature we are trying to detect here.

We conclude that as far as Fanno modeling is concerned, the resolution of our thermocouple system is inappropriate for a proper characterization of the apparatus in that mode. For the sake of Fanno modeling, we also conclude that the pressure measurements must dictate the calculation of the temperature field. For low speed flow modeling with a two-phase fluid or even a perfect gas, significantly higher resolution thermocouple measurements are required, though those instruments may not be suitable for heated flow experiments (especially in perfect gas experiments), our main goal here.

Based on the data shown above, using pressure to predict temperature, the roughness level of the apparatus falls somewhere between those of "drawn 


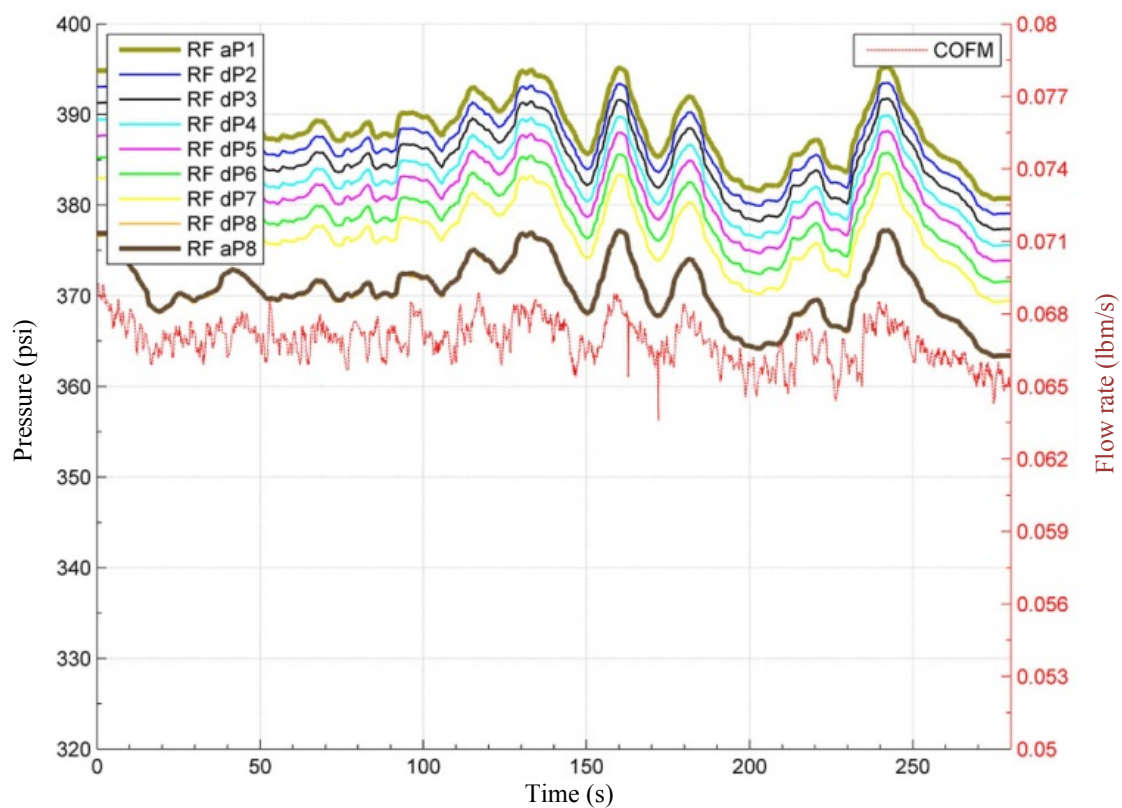

Fig. 10 Pressures at Station 1 through Station 8, plus the mass flow rate (COFM) from the Coriolis mass flow meter, for Run \#1.

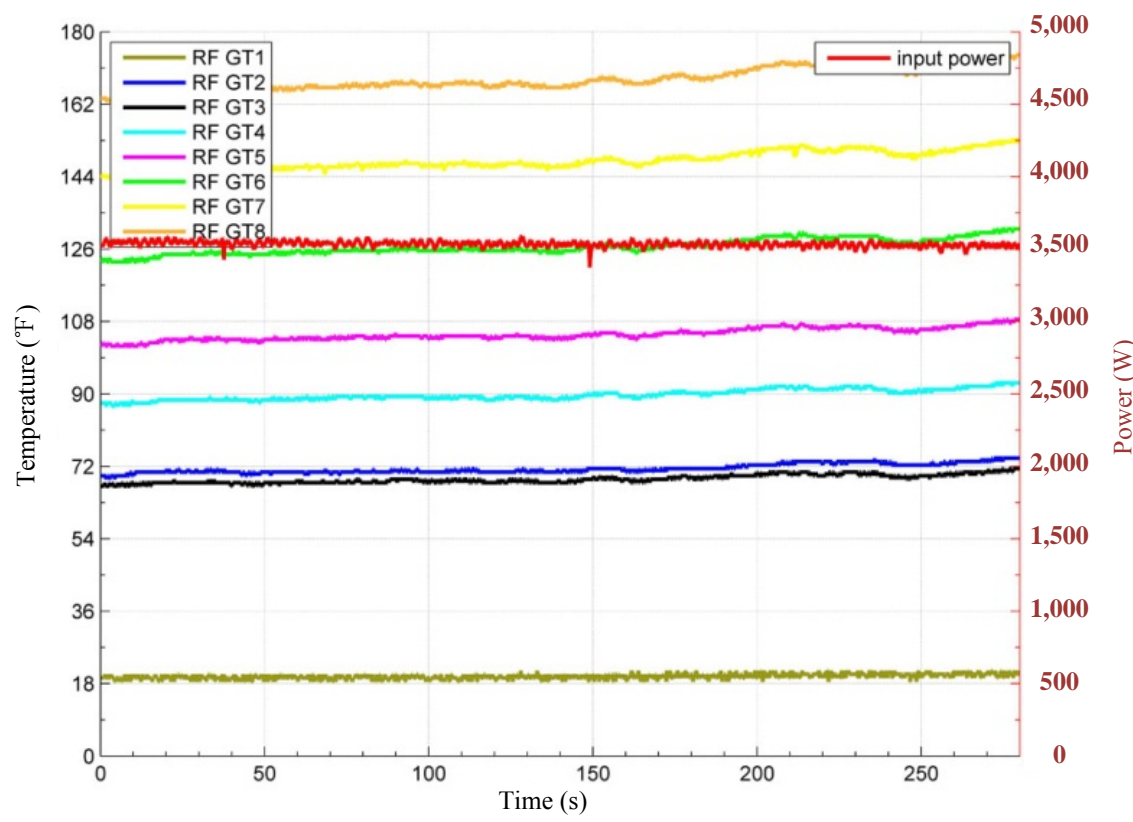

Fig. 11 Air temperatures at Station 1 through Station 8, plus the input power (nominally 3.5 kW for this test), for Run \#1.

copper tubing" and "glass". In other words, very smooth pipe walls, despite the instrument penetrations, and therefore suitable for pure Rayleigh flow experiments.

\subsection{Rayleigh Flow Analysis}

There are two fundamental elements of analysis for heat-driven (Rayleigh) flows: first, there is no pressure loss due to friction along the apparatus; and second, all heat added is properly accounted for. The first requirement was verified during our Fanno flow tests. The second requirement is investigated here.

Certain assumptions must be made with respect to the apparatus before this analysis can be carried out. For instance, we assume that the temperature change in the fluid is consistent with a purely radial heat flux 


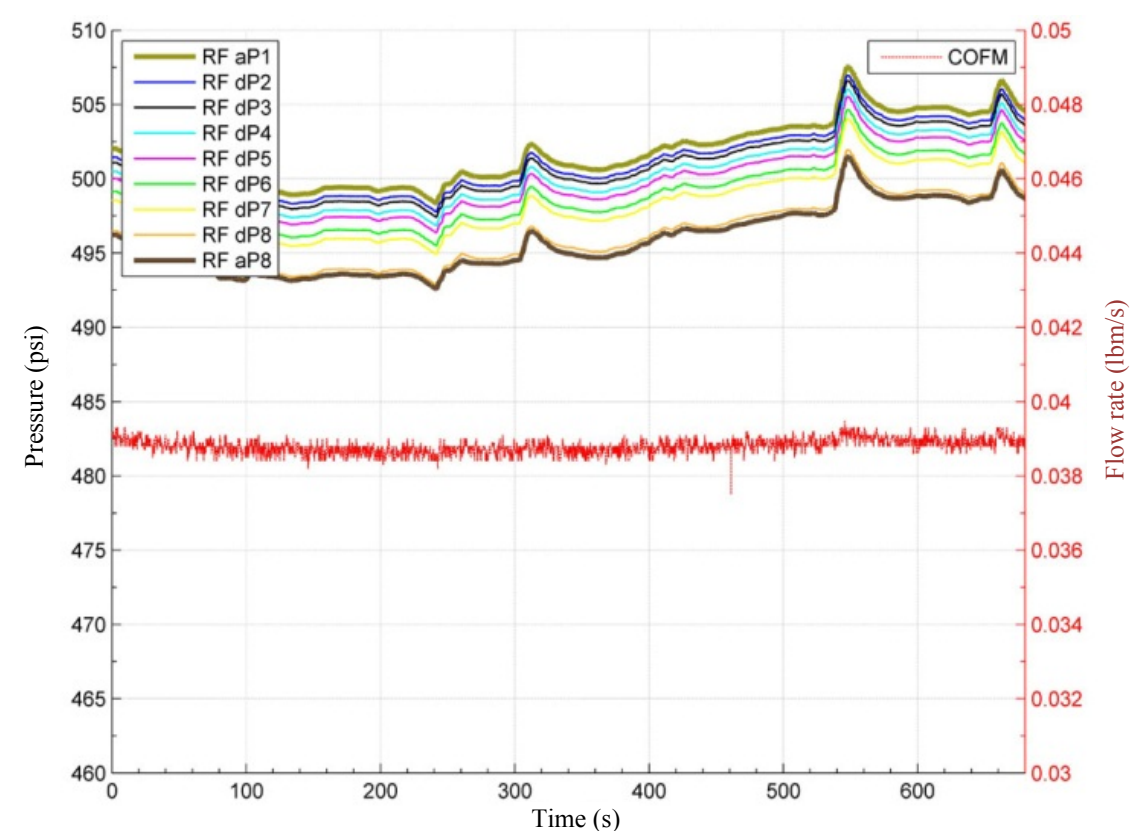

Fig. 12 Pressures at Station 1 through Station 8, plus the mass flow rate (COFM) from the Coriolis mass flow meter, for Run \#2.

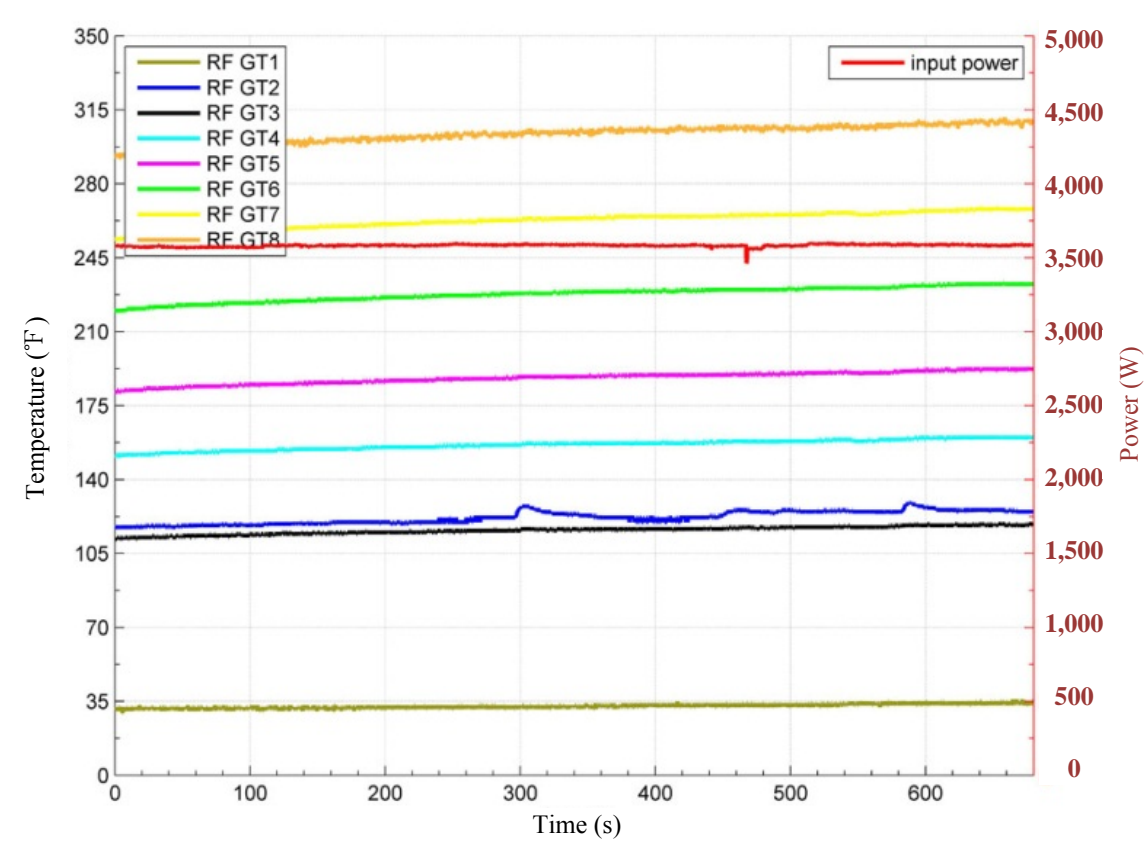

Fig. 13 Air temperatures at Station 1 through Station 8, plus the input power (approximately 3.5 kW), for Run \#2.

through the pipe to the fluid, though this is not the case. Figs. 14-16 illustrate how this assumption may cause an error in measurements, because of the relatively low axial thermal resistance of the copper tubing. Fortunately, with the types of fluids being tested in the Rayleigh experiments of concern here (turbulent regime helium and two-phase flows), the convective heat transfer coefficients are high, so that the effective Biot number of the apparatus remains high enough that convection may be expected to dominate axial conduction. Still, an axial heat loss through the ends of the apparatus may be expected.

Heat flux to the apparatus is provided by a series of electric heaters that generate a total of approximately 


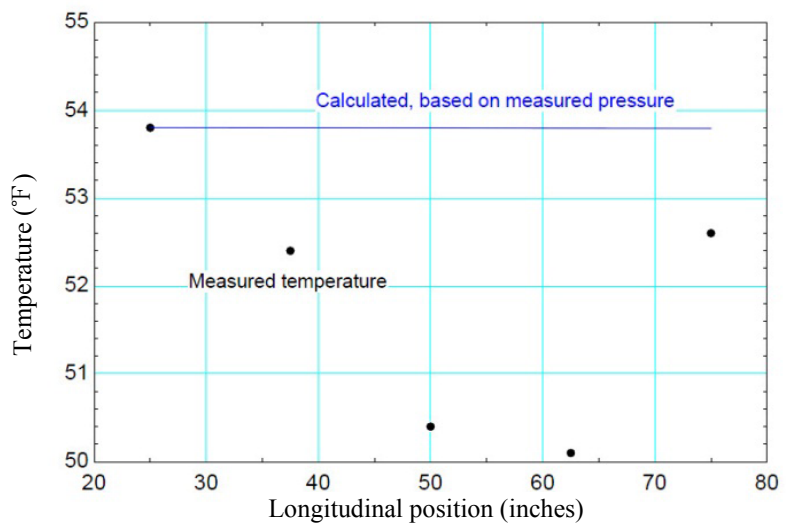

Fig. 14 Comparison of calculated temp erature in the Rayleigh apparatus (in "Fannomode" inblue), using the measured pressure, as compared to the actual measured temperature (in black).

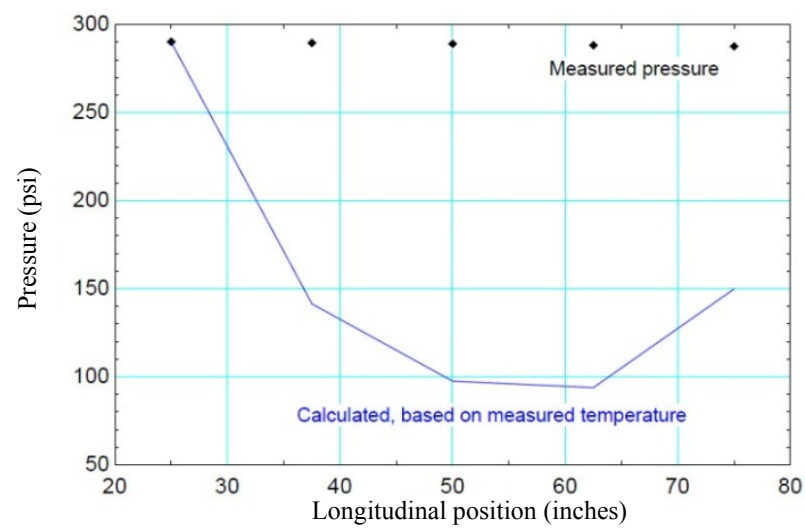

Fig. 15 Calculated pressure (in blue) based on the measured temperature, versus the actual measured pressure.

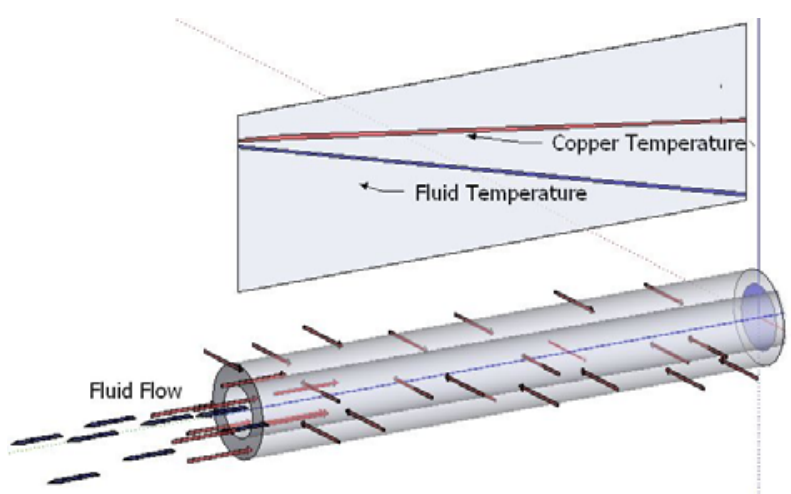

Fig. 16 Heat transfer modes in the apparatus. Some heat may be transferred axially upstream through the copper pipe (i.e., heat conduction, left to right).

3, $500 \mathrm{~W}$ along the insulated pipe surface, which works out to $52 \mathrm{~W} / \mathrm{in}^{2}$ of pipe area exposed to the heated gas. The expected temperature of the gas as a function of axial distance along the pipe is therefore:

$$
T(x)=T_{1}+\left(\frac{\pi D \dot{q}^{\prime \prime}}{\dot{M} C_{p}}\right) x
$$

where, $D$ is the inner diameter; $q^{\prime \prime}$ is the heat flux (52 W/in $\left.{ }^{2}\right) ; \dot{M}$ is the mass flow rate; and $C_{p}$ is the specific heat of the gas. Moreover, since the mass flux is constant, the pressure may also be modeled implicitly by an energy balance to give:

$$
P(x)\left[\frac{C-P(x)}{R \cdot G^{2}}\right]=T_{1}+\left(\frac{\pi D \dot{q}^{\prime \prime}}{\dot{M} C_{p}}\right) x
$$

with:

$$
C=P_{1}+\left(\mathrm{R} \cdot G^{2}\right)\left(T_{1} / P_{1}\right)
$$

This model (independent of fluid temperature downstream of the first thermocouple) allows us to determine the total level of heat loss of our apparatus, through three possible loss paths: (1) radially through the insulation; (2) axially through the end caps; and (3) axially along the copper tube itself.

To illustrate the results of this analysis, we present two runs performed with heated helium, corresponding to two different flow rates: 0.0110 $\mathrm{lb}_{\mathrm{m}} / \mathrm{sec}$ (Run \#12, see Fig. 17), and $0.0145 \mathrm{lb}_{\mathrm{m}} / \mathrm{sec}$ (Run \#18, see Fig. 19). The expected temperature plots, based on Eq. (7) above, are then modified to account for heat loss through the apparatus, until the curve matches the data points. Both runs showed good agreement when corrected assuming a $22 \%$ loss of nominal heat input, as shown in Figs. 18-20. Using that constant heat loss factor, both runs show good agreement with the theoretical prediction. The copper surface temperatures varied between $173{ }^{\circ} \mathrm{F}$ and $190^{\circ} \mathrm{F}$ for the low flow rate run (Run \#12) and $142{ }^{\circ} \mathrm{F}$ and $256^{\circ} \mathrm{F}$ for the higher flow rate run (Run \#18), giving us an estimate for the temperature tolerance of the heat loss characteristics of the apparatus, which may also be applied to test runs using a less-well characterized test gas, such as $\mathrm{N}_{2} \mathrm{O}$.

\section{Preliminary Predictive Model for $\mathrm{N}_{2} \mathrm{O}$ Behavior}

For two-phase flows, the CHF is defined as the 


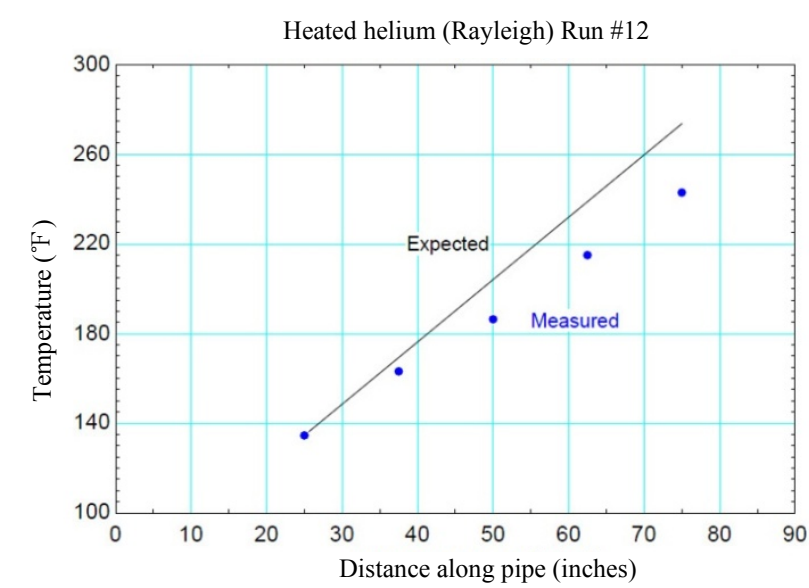

Fig. 17 Low mass flow rate heated helium test.

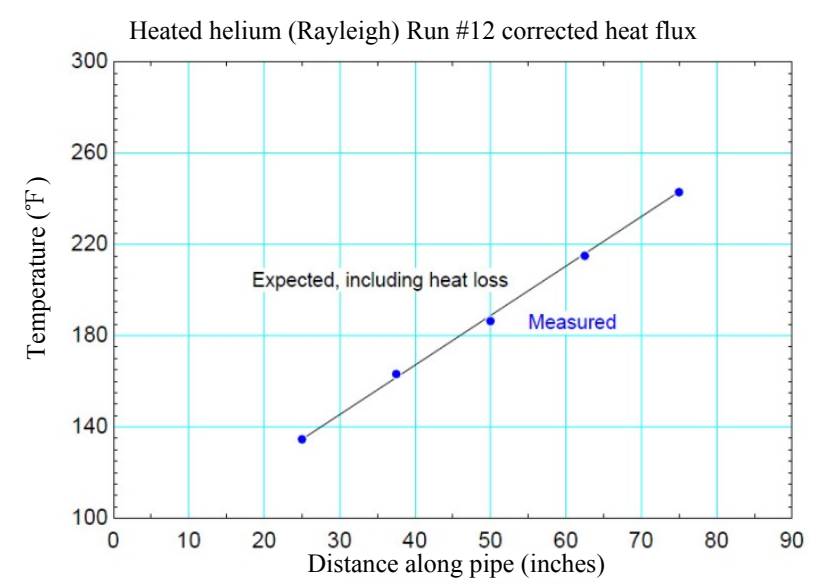

Fig. 18 Same run, modeled using $78 \%$ of the actual heat input to the flow.

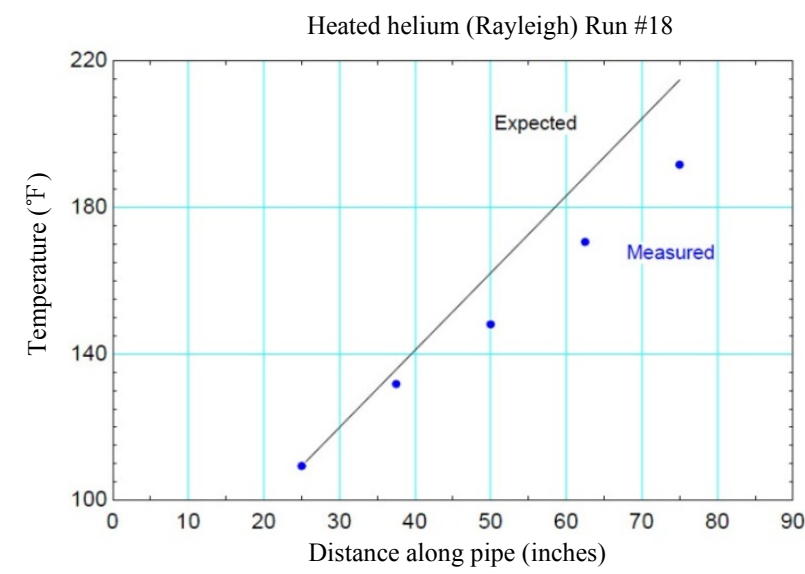

Fig. 19 High mass flow rate, heated helium test. Once again, the modeled temperature distribution overestimates the actual, measured temperature as a result of heat loss through the apparatus.

heat load above which the liquid phase will no longer wet the walls of the pipe. If the applied heat flux exceeds this value, the flow is classified as film boiling

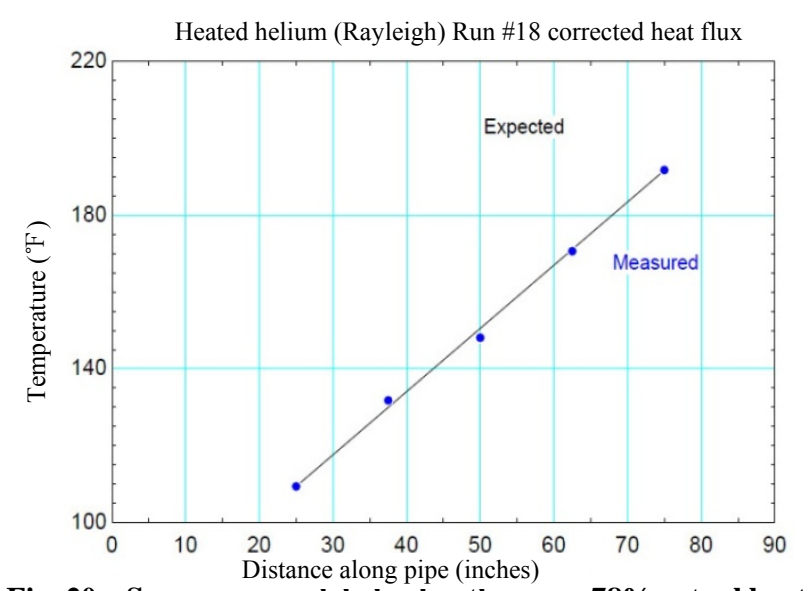

Fig. 20 Same run, modeled using the same $78 \%$ actual heat input to the flow, as used in the low flow rate experiment model.

rather than flow boiling. In flow boiling, the critical heat flux is a function of thermodynamic quality. As a fluid moves through a heated pipe and is evaporated, the quality increases. This results in a decrease in CHF. If the fluid remains in the pipe long enough, the applied heat flux will eventually exceed the critical heat flux. The location in the pipe at which this occurs is called the "dryout" point. As is the case in pool boiling, dryout in flow boiling results in an increase in surface temperature and is generally avoided.

There are two types of dryout. If the fluid is low quality at the point of dryout, IAF occurs in which a liquid core is surrounded by a vapor ring. The second type of dryout is termed mist flow in which the fluid simply breaks into small droplets and is suspended in a vapor bulk. This type of dryout, which is the most likely for our $\mathrm{N}_{2} \mathrm{O}$-cooling applications, typically occurs at high qualities when the fluid is in the annular flow regime prior to mist flow dryout. Note that heat transfer coefficients in the mist flow regime are considerably higher than those in the IAF regime. Similarly, the observed wall temperatures are much lower in mist flow than IAF. This is due to the fact that mist flow liquid is able to intermittently wet the walls of the pipe, which is not the case in IAF.

An analytical dryout model for $\mathrm{N}_{2} \mathrm{O}$ was developed to be used to predict the flow state in the current experimental apparatus. This model represents the 
two-phase flow of $\mathrm{N}_{2} \mathrm{O}$ as comprised of a homogeneous fluid, that is, the properties of the two phases are averaged over each cross section of the pipe. In this way, a one-dimensional flow assumption is made that allows single-phase fluid dynamic principles to be applied. This model ran for two cases, each case having an $\mathrm{N}_{2} \mathrm{O}$ saturation pressure of 365 psia and a heat input rate of $3.32 \mathrm{BTU} / \mathrm{s}(3.5 \mathrm{~kW})$, but with the two cases having different mass flow rates: $0.05 \mathrm{lb}_{\mathrm{m}} / \mathrm{s}$ and $0.25 \mathrm{lb}_{\mathrm{m}} / \mathrm{s}$, respectively.

Results for the low flow rate case, $\dot{M}=0.05 \mathrm{lb}_{\mathrm{m}} / \mathrm{s}$, are shown in Figs. 21-25. As is expected, the $\mathrm{N}_{2} \mathrm{O}$ quality increases as the $\mathrm{N}_{2} \mathrm{O}$ travels along the pipe, reaching almost $85 \%$ at the exit. Friction is ignored in the homogeneous model, so the pressure drop along the pipe is solely due to the heat added. The total pressure drop along the Rayleigh pipe more than 7 feet is approximately 1 psi for the low flow rate case, which is on par with the predicted Rayleigh pressure drop for the other models presented herein. Since the quality remains less than one, the $\mathrm{N}_{2} \mathrm{O}$ remains saturated, and accordingly, the temperature is seen to drop as the pressure drops. As the $\mathrm{N}_{2} \mathrm{O}$ evaporates as it flows along the pipe, it cools the copper walls of the pipe, which are simultaneously being heated. As a function of distance along the pipe, the copper wall temperature first drops slightly, and then begins to rise at an increasing rate as the $\mathrm{N}_{2} \mathrm{O}$ quality approaches one. The heat transfer coefficient as a function of distance along the pipe is shown in Fig. 25. As is expected, the heat transfer coefficient decreases as the quality increases. Notice that there appears to be a slight maximum at about 12 inches into the pipe, which corresponds to the location of the minimum wall temperature. The $\mathrm{N}_{2} \mathrm{O}$ quality at this location has a value of about $25 \%$.

In general, two-phase flows will dryout prior to reaching the saturated vapor line [3]. A significant limitation of the homogeneous flow model used by itself is that it includes no mechanism for determining dryout, other than simply assuming that it occurs right at the saturated vapor line. As heat transfer coefficients are much higher in the nucleate boiling regime than that in the mist flow or film boiling regime, this method will likely over predict heat transfer coefficients and under predict wall temperatures. It is therefore a very rudimentary approach, but it does provide an upper bound for when dryout occurs. And in the low flow rate case, dryout in the actual system would likely occur for quality in the range between $50 \%$ and $70 \%$, corresponding to 40 inches and 65 inches into the pipe.

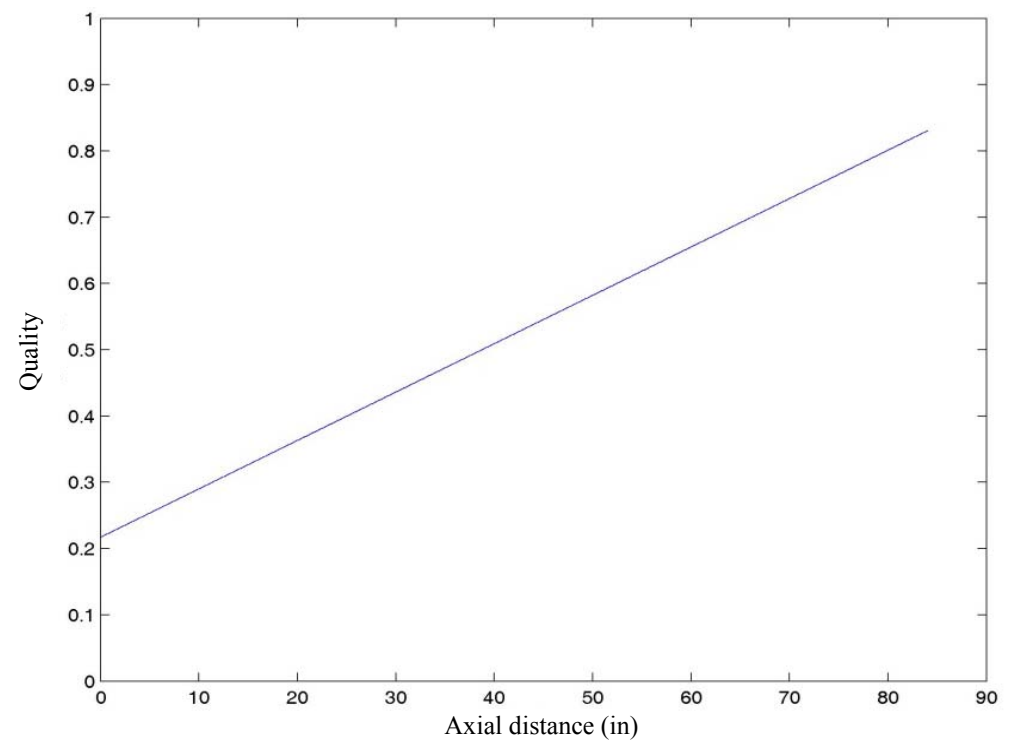

Fig. 21 Predicted $\mathrm{N}_{2} \mathrm{O}$ quality along the pipe for the low flow rate case. 
Development and Test of an Experimental Apparatus to Study Thermal-Choking in IDEAL GASES and Self-decomposition in Superheated $\mathrm{N}_{2} \mathrm{O}$

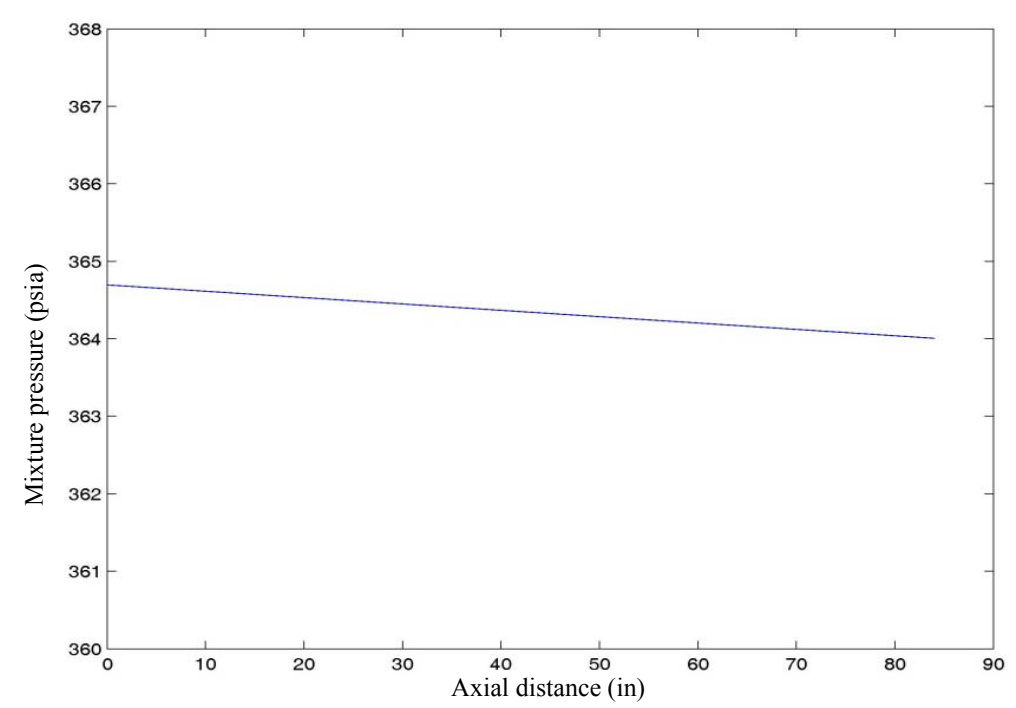

Fig. 22 Predicted $\mathrm{N}_{2} \mathrm{O}$ pressure along the pipe for the low flow rate case.

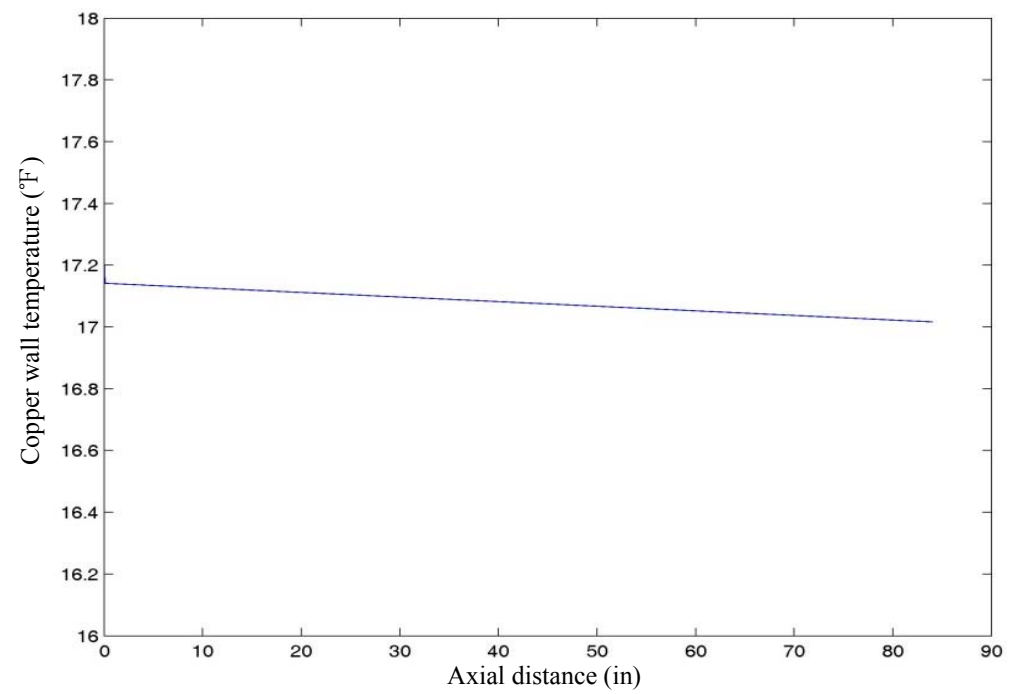

Fig. 23 Predicted $\mathrm{N}_{2} \mathrm{O}$ temperature along the pipe for the low flow rate case.

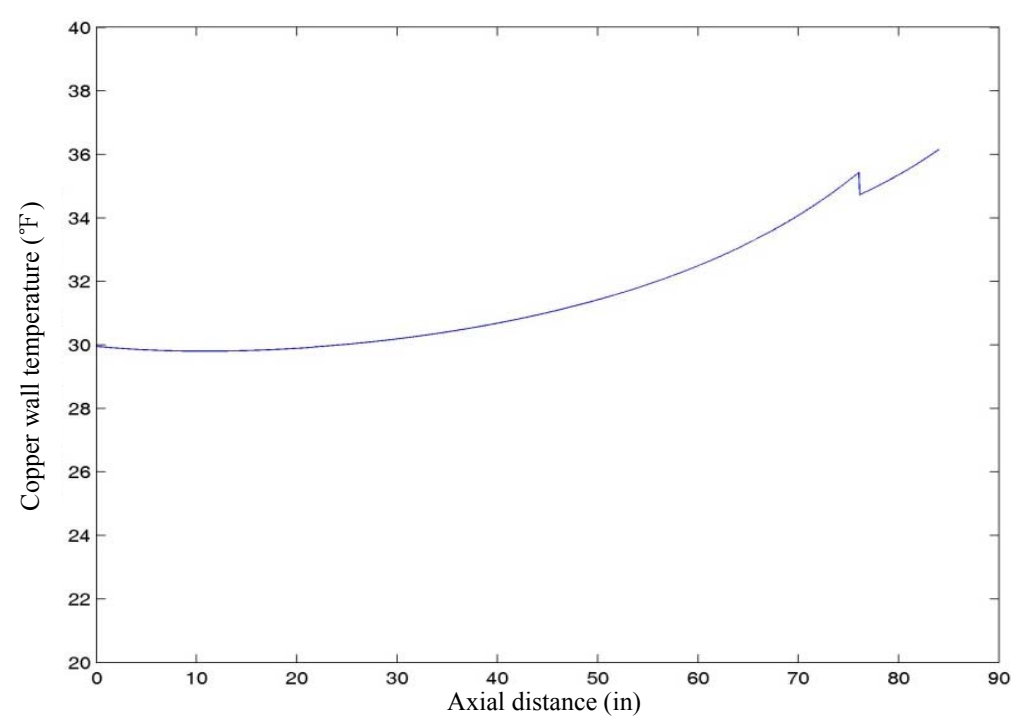

Fig. 24 Predicted copper wall temperature along the pipe for the low flow rate case. 


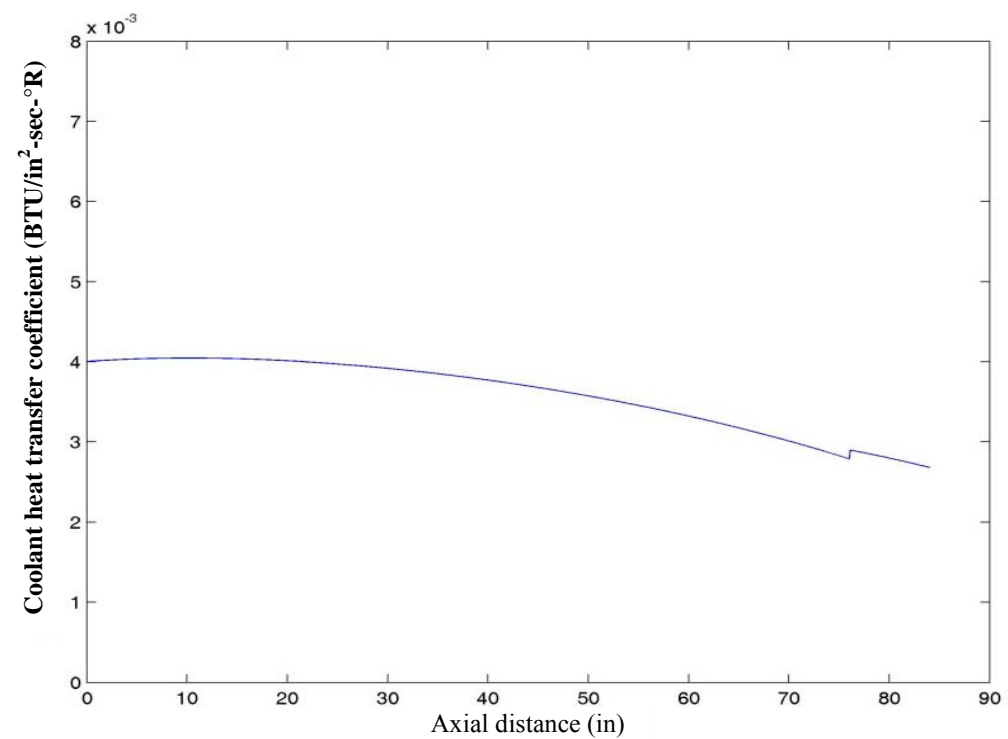

Fig. 25 Predicted heat transfer coefficient along the pipe for the low flow rate case.

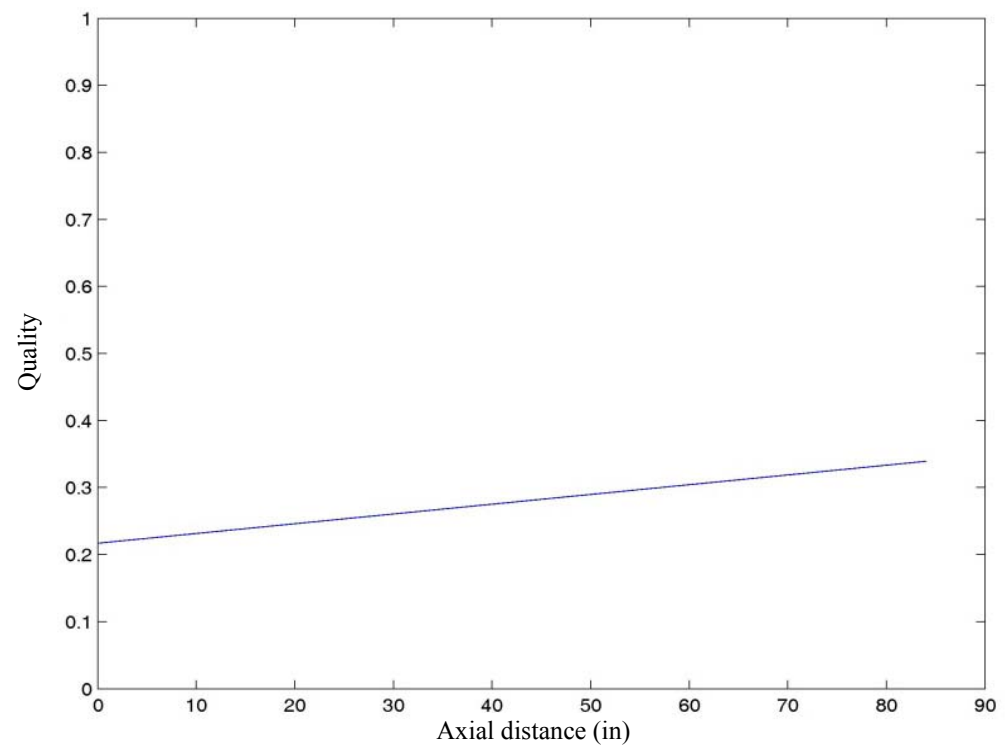

Fig. 26 Predicted $\mathrm{N}_{2} \mathrm{O}$ quality along the pipe for the high flow rate case.

Results for the high flow rate case, $\dot{m}=0.25 \mathrm{lb}_{\mathrm{m}} / \mathrm{s}$, are shown in Figs. 26-30. The overall results for the high flow rate case differ from those for the low flow rate case differ in the manner expected due to the greater cooling capacity available, for the constant input heating rate. The $\mathrm{N}_{2} \mathrm{O}$ quality reaches $35 \%$ at the exit, indicating that dryout likely would not be reached in the real apparatus under these flow conditions. The Rayleigh pressure drop remained small at approximately 3.5 psi, although it more than tripled from the low flow rate case. Since the quality remains less than one, the
$\mathrm{N}_{2} \mathrm{O}$ remains saturated, and accordingly, the temperature is seen to drop as the pressure drops. As in the low flow rate case, as the $\mathrm{N}_{2} \mathrm{O}$ evaporates as it flows along the pipe, it cools the copper walls of the pipe, which are simultaneously being heated. However, in this case, evaporation of the $\mathrm{N}_{2} \mathrm{O}$ provides enough cooling to keep the temperature of the copper wall dropping slightly as a function of distance along the pipe. The heat transfer coefficient as a function of distance along the pipe is shown in Fig. 30. In a practical sense, the heat transfer coefficient is essentially constant in this 

Self-decomposition in Superheated $\mathrm{N}_{2} \mathrm{O}$

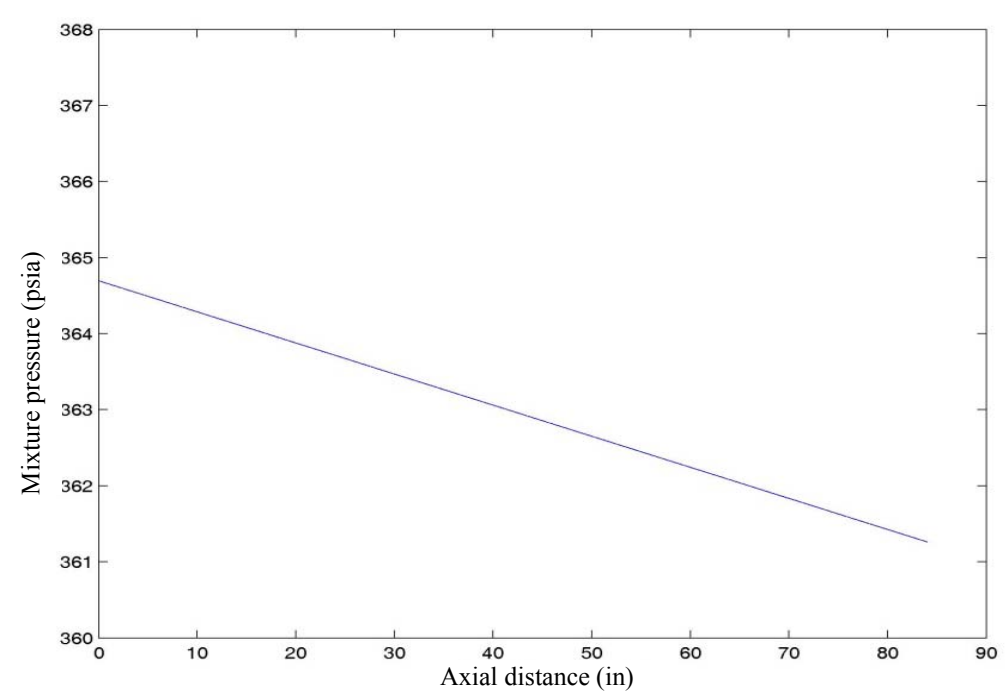

Fig. 27 Predicted $\mathrm{N}_{2} \mathrm{O}$ pressure along the pipe for the high flow rate case.

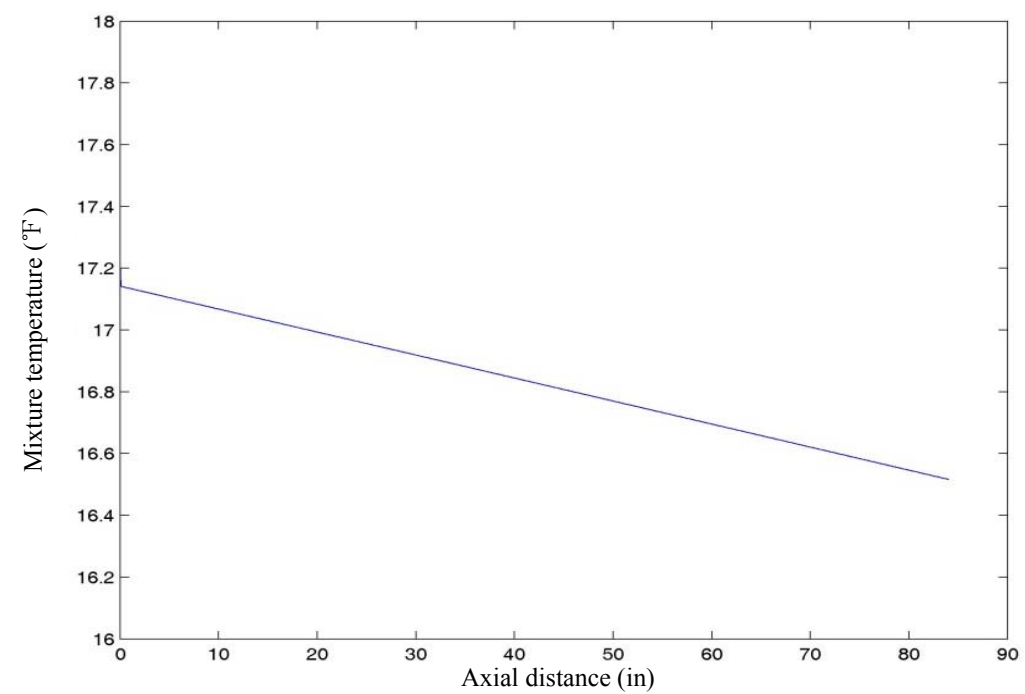

Fig. 28 Predicted $\mathrm{N}_{2} \mathrm{O}$ temperature along the pipe for the high flow rate case.

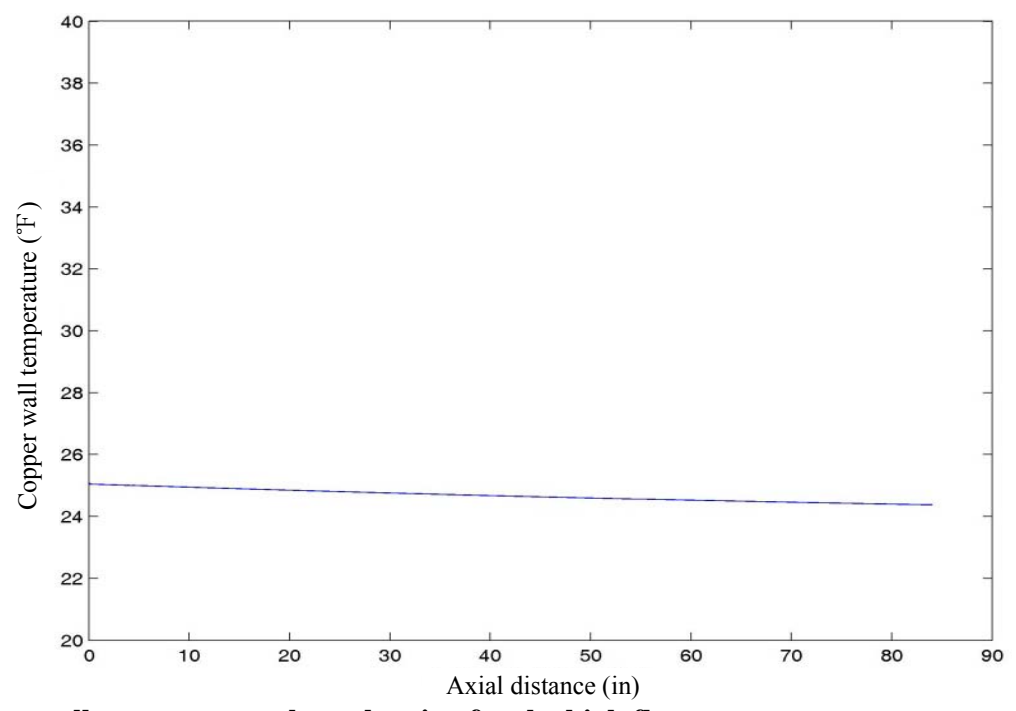

Fig. 29 Predicted copper wall temperature along the pipe for the high flow rate case. 


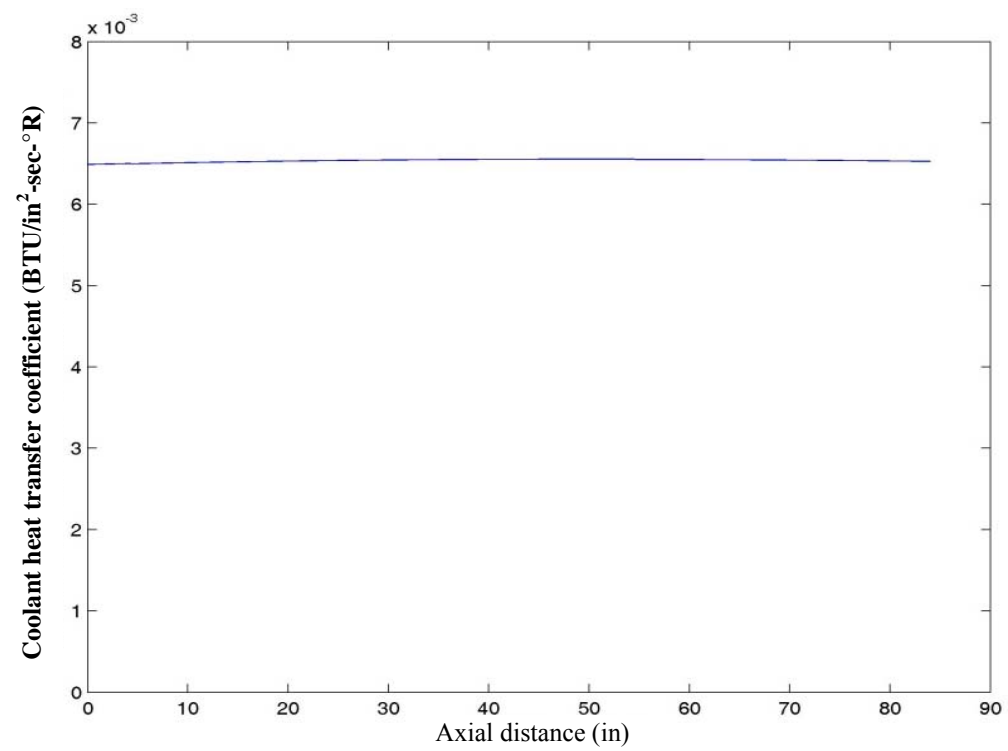

Fig. 30 Predicted heat transfer coefficient along the pipe for the high flow rate case.

case. However, a close examination of the details in Fig. 30 does show that again a slight maximum occurs at the location where the $\mathrm{N}_{2} \mathrm{O}$ quality has a value of about $25 \%$. Whether the existence of this maximum is due to parameter changes with respect to temperature or a strange ramification of the homogeneous model is unknown at this point. The apparent discontinuities in wall temperature and heat transfer coefficient, which appear in both the low and high flow rate cases, are attributed to the discontinuous nature of the Shah heat transfer correlation used in the model.

\section{Acknowledgments}

The assistance of Mr. Terry Cooke and Mr. Jim Gerhardt, both of Cal Poly State University, in helping to design and conduct the experiments in this project is gratefully acknowledged. Michael Kerho, Chief Aerodynamicist with Rolling Hills Research, also contributed to the modeling of the experiments and this help is greatly appreciated. Portions of this work were carried out under NASA STTR Contract NNX11C107P [4]. The authors gratefully acknowledge this support.

\section{References}

[1] Karabeyoglu, A., Dyer, J., Stevens, J., and Cantwell, B. 2008. "Modeling of $\mathrm{N}_{2} \mathrm{O}$ Decomposition Events." Presented at the Proceedings of the 44th AIAA/ASME/SAE/ASEE Joint Propulsion Conference \& Exhibit, Hartford.

[2] Zucker, R. D., and Biblarz, O. 2002. Fundamentals of Gas Dynamics, 2nd ed.. Chichester: John Wiley and Sons.

[3] Chen, J. C. 1966. "Correlation for Boiling Heat Transfer to Saturated Fluids in Convective Flow." Industrial Engineering Chemistry Process Design and Development 5 (3): 322-9.

[4] Murray, W. R. 2010. "A Refined Model for the Behavior of Nitrous Oxide $\left(\mathrm{N}_{2} \mathrm{O}\right)$ to Assess the Limits of $\mathrm{N}_{2} \mathrm{O}$ Cooling.” NASA STTR Phase I Grant. 